\title{
O que é, ou que que vem a ser, o casamento ? Questões de gênero na literatura do oitocentos
}

\section{What is, or that which comes to the wedding? Gender issues in eighteenth- century literature.}

Artigo

Original

Rogério N. Afonso ${ }^{1}$

Original

Paper

\section{Palavras-chave}

Casamento

Família

Gênero

\section{Resumo}

Partindo de um conto Machadiano que aborda o tema do casamento, buscamos explicitar as relações de gênero que permeiam essa instituição no Brasil, constituindo para tal abordagem um apanhado de ideias presentes em textos de escritores brasileiros atuantes no século XIX, atentando para as formas de representação da instituição "família" no período, bem como as transformações que esta tendeu a assimilar e cristalizar.

\section{Abstract}

Based on a "Machadiano" tale that addresses the theme of marriage, we try to expose gender relations that permeate the institution in Brazil,constituting such an approach taken by these ideas in the texts of Brazilian writers active in the nineteenth century, paying attention to the ways of representing the "family" institution in the period, and the transformations that this tended to assimilate and crystallize.

Key words

Marriage

Family

Gender
Recebido em 09/2011

Aprovado em 08/2012

"Onde queres família, sou maluco. E onde queres romântico, burguês. Onde queres Leblon, Sou pernambuco.

E onde queres eunuco, garanhão. Onde queres o sim e o não, talvez (...)"

Caetano Veloso 
Em um pequeno conto machadiano intitulado "A curiosidade", publicado originalmente no periódico carioca "A estação" - destinada ao público feminino - em 1879, e tomado aqui em uma reprodução on-line de suas obras completas ${ }^{2}$, a principal personagem: Carlota - uma jovem mulher, noiva de um igualmente jovem e promissor negociante da cidade - vê-se curiosa ao ler um anúncio de um espetáculo teatral que se aproxima:

O título da peça era uma pergunta: O que é o casamento ? A peça era de Alencar e ia a cena pela primeira vez...

- O que é o casamento ? Repetiu a moça consigo; título singular... Quando é a representação? (ASSIS apud ABRAMO, 2011)

A estranheza da moça frente à questão, que já não parece ser uma novidade em meados do século XIX, visto que dois grandes observadores da sociedade da Corte no Rio de Janeiro - Machado de Assis e José de Alencar, cada um a seu modo - vieram a se debruçar sobre ela, pode ser vista hoje pela historiografia sob vários aspectos e, mesmo partindo de diferentes abordagens. Este artigo é parte da investigação feita para pesquisa de mestrado em História pela Universidade Federal do Espírito Santo, intitulada "A dimensão política na dramaturgia de José de Alencar", na qual buscamos, por meio da análise dos textos teatrais de Alencar ampliar as possibilidades da pesquisa histórica, tendo por base o uso da literatura. A análise dos textos teatrais escritos ou simplesmente adaptados por autores brasileiros ao longo do século XIX possibilitam uma apreciação significativa do cotidiano da burguesia da Corte no período. Os textos tratam de temas os mais diversos: o casamento, o comércio, os problemas decorrentes da escravidão, o trabalho, a casa, a família, a vida. Nosso objeto de estudo é esse cotidiano da família burguesa que toma forma no período de estabilidade socioeconômica conseguido nas primeiras décadas do segundo império.

Para o fim de uma melhor compreensão, seguiremos a narrativa de Machado como um guia para nossa análise, o que, podemos dizer, é parte da proposta do texto. Explicamos: caracterizado como propaganda ou mesmo uma forma de educação, os sentidos atribuídos ao teatro são vários no período em questão. Essa forma de expressão artística foi bem aceita pela sociedade dos oitocentos, não só como forma de lazer, mas como uma opção para a "educação social" da população. Para que tivesse algum valor literário, um espetáculo teatral deveria concorrer para a instrução, o enobrecimento e a formação moral da sociedade. Segundo Machado de Assis:

O drama, sem sair dos limites imparciais da arte, tem uma missão nacional, uma missão social e uma missão humana.

(...) cumpre que o povo não saia do teatro sem levar consigo alguma moralidade austera e profunda. (ASSIS apud ABRAMO, 2011)

Aqui, em nosso caso, o debate vem em torno da família e do casamento como uma das formas de sua construção. O casamento é uma instituição antiga, nascida dos costumes e constituída na tradição. Na atualidade, incorporada ao direito pátrio. No sentido social, pode ser entendido como uma manifestação da vontade conjunta que, a partir de uma cerimônia civil legitima uma união entre pessoas. Uma família, ainda a partir do direito, nasce do casamento válido e, este é precedido e finalizado com os requisitos que a lei estabelece. O Art. 226 da Constituição Federal reza que “ a família, base da sociedade, tem especial proteção do Estado" (BRASIL,1988). Portanto, sendo um contrato entre partes, deve estabelecer as normas e regulamentos legais como qualquer outro, mas que determina, como vimos, as bases das relações da sociedade.

Passemos rapidamente por um exame nas estruturas familiares brasileiras e suas mudanças, partindo do período colonial até o advento da família conjugal moderna, constituída a partir da segunda metade do século XIX. A chamada família patriarcal, analisada por Gilberto Freire e Antônio Cândido de Mello e Souza se

2 O conto foi publicado originalmente na revista "A estação". Um periódico que buscava ter como alvo o público feminino da Corte no Rio de Janeiro em meados do séc. XIX. A seletividade já parte daí: mulher, letrada, abastada, com algum tempo livre para a leitura não deveria haver muitas... 
constitui, segundo Mariza Corrêa, como um "modelo ideal", dominante já no período da colonização. Ela se instala nas regiões onde foram implantadas as grandes unidades agrárias de produção - engenhos de açúcar, fazendas de criação de gado, plantações extensivas de café - e mantém-se através da incorporação de novos membros - de preferência parentes legítimos ou ilegítimos - aos extensos clãs, o que assegura a indivisibilidade de seu poder. $\mathrm{O}$ chamado "patriarca" elevava eu prestígio social e político a medida que agregava uma maior quantidade de pessoas sob sua influência, daí a importância dos extensos laços de família e outras associações possíveis derivadas, como por exemplo a prática de apadrinhamento - pelo patriarca - de dezenas de pessoas, muito comum na zona rural, o que só vinha a aumentar o seu prestígio. Antônio Cândido - como nos mostra também Corrêa - chega a afirmar que este é o tipo de família, existente no Brasil do século XVI ao XIX, de onde se deriva toda a formação social do Brasil (CORREA, 1993. p. 16).

A sociedade colonial nesse recorte de 300 anos esteve composta por duas partes: uma familiar (a família patriarcal) e outra não familiar, que reunia a maioria da população, a massa anônima dos socialmente degredados, daqueles rejeitados pelos grupos familiares e criados fora deles (CÂNDIDO, 2011). Dentro dessa categoria encontramos residências onde viviam padres e suas afilhadas, junto a escravas e concubinas e comerciantes solteiros que viviam em trânsito constante entre Brasil e Portugal e não se preocupavam em constituir uma família por aqui. Temos a presença de viúvas com seus filhos, que poderiam viver em concubinato e manter-se sem ajuda econômica e não se importando com sua moral constituída. Situações em que o casal de cônjuges divide o teto com uma concubina do marido, com filhos legítimos e, criados todos juntos. Era comum, em habitações relativamente pequenas em área urbana, em que os poucos escravos existentes dividissem também o espaço da casa para o descanso noturno. Uma família, pela distância relativa entre as moradias num território imenso e pouco povoado, se fechava em si, com um convívio muito pequeno com outros grupos. A figura da comunidade se tornava algo abstrato, dada a dificuldade de encontrar-se com um vizinho, outro grupo familiar ou algo assim. A família se bastava.
Havia uma criação de animais - quando em área rural, mesmo que não tão distante de um núcleo urbano - e plantações que garantiam a subsistência, e até mesmo algum mobiliário doméstico, bastante simples, era fabricado em pequenas oficinas que eventualmente existissem na casa. Os excedentes de produção poderiam ser trocados depois, mas isso não representava efetivamente uma relação comercial. A vida existia nos limites da família, salvo algumas festas religiosas organizadas pelas diversas irmandades presentes no Brasil, onde as pessoas podiam, além de assistir às cerimônias, se relacionar com outras, comprar algumas novidades dos caixeiros viajantes que estavam sempre presentes em tais acontecimentos, tendo assim algum princípio de uma vida social, de resto o cotidiano era bem limitado.

No Brasil colonial, o português tomava para si as mulheres indígenas e negras - tanto as escravas como as libertas - para a prática do concubinato ou mesmo para torná-las esposas, sendo que o casamento era algo bem menos comum. Chegavam aqueles homens, em sua grande maioria solteiros ou desacompanhados de suas famílias, se eventualmente as houvesse na Europa. Não é possível buscar, em um país com extensão geográfica continental e diferenças gritantes entre os grupos rural e urbano - que só tendiam a aumentar nos primeiros séculos no Brasil - um padrão de vida e de organização familiar mesmo dentro de segmentos determinados da população. $\mathrm{Na}$ verdade, o que se vê nesse momento deve ser entendido como, segundo o texto de Cristiane Matos (MATOS, 2008), uma apropriação de um modelo importado do velho continente, tradicionalmente constituído, e adaptado ao clima e as particularidades das diversas etnias que aqui vem se miscigenando através do tempo. O elemento branco, masculino, europeu, cristão, se torna também aqui, no Brasil, o modelo a ser seguido e obedecido. É certo que a igreja católica incentivava o casamento como uma forma de legitimar as relações dos colonos com os naturais da terra, mas nem sempre tal projeto funcionava como regra.

A construção simbólica, como sugerida por Scott (SCOTT 2008), passaria pela formação de dois tipos distintos de mulher: Eva e Maria. Uma, a portadora do mal, do pecado, e a outra como um modelo de virtude a ser seguido a partir de 
uma série de normas e procedimentos que auxiliam na legitimação da repressão da sexualidade feminina. Modelos que são socialmente aceitos e, em consequência, cobrados às mulheres pelo grupo social. Dentro desse modelo de família, "o destaque para a autoridade do marido, exibia uma esposa submissa que tinha por tarefa o desempenho de atividades restritas (...) O que se esperava é que estivesse preparada para exercer o papel de esposa e de mãe da prole legítima do patriarca (MATOS 2008, p. 22).

O casamento definia as relações entre mulheres e homens e se caracterizava pela ideia de preservação de interesses dos grupos de parentesco. As uniões entre indivíduos de um mesmo grupo fortaleciam os laços entre estes e garantiam a conservação dos bens, terras e status social. Fortalecia também os conceitos de formação de famílias que já vinham sendo construídos por várias gerações no Brasil.

Não parecia ser esse o futuro aguardado por Carlota - carregado de submissão e descontentamento. Dona Fausta, sua mãe, com certo desdém, ouve a interrogação da menina Carlota e, com alguma empatia (ou por causa dela), busca construir da melhor forma uma resposta, tendo considerado que o casamento é como uma loteria - no dito popular. Mas, haveria sempre um meio de conseguir o prêmio maior: “ - (...) ser uma boa esposa”, afirma !(ASSIS apud ABRAMO, 2011).

A fala de D. Fausta condiz com os valores assimilados por sua geração: uma mulher da família abastada, residente na corte do Rio de Janeiro no início do século XIX, cristã fervorosa que acaba por, inconscientemente, reproduzir a moral da família, baseado na inferioridade da mulher e na dominação construída pela instituição do patriarcado.

Segundo Saffioti (SAFFIOTI, 1992), toda sociedade revela alguma dominação masculina, mesmo que esta possa variar conforme a época, a constância e a intensidade. Mas essa dominação é, de fato, uma relação integrativa que tende a preservar a figura dominada. O casamento, enquanto evento constitutivo da família, estabelece a relação de poder entre os gêneros, sua aceitação ou não e uma consequente resistência. Homem e mulher desem- penham papéis sociais aos quais foram socialmente destinados; esses modelos garantem a inserção do indivíduo no espaço coletivo.

O Homem deve ser o símbolo da força e virilidade, enfrentando o ambiente público adverso. A mulher, ao contrário, deve se restringir ao espaço doméstico, tendo sempre uma atitude passiva e discreta frente ao homem e ao meio. São tais mitos de virilidade e feminilidade que sustentam as diferenças hierárquicas de papéis do homem e da mulher. A família, através de suas diversas constituições, é um agente reprodutor de padrões culturais, e, aqueles que buscam seguir um outro caminho, que não o padronizado, sofrem a discriminação do grupo. Enfatizando diferenças biológicas, criam diferenças comportamentais que constituem os personagens sociais.

O sexo está no plano biológico e o gênero está no espaço da cultura. Devemos entender o gênero como uma construção social das diferenças entre o masculino e o feminino, por meio de práticas, discursos, ideologias ${ }^{3}$ dos diferentes grupos sociais. Na referência dada por Simone de Beauvoir (BEAUVOIR, 1970), a mulher não nasce mulher, ela vai se tornar uma mulher dentro da sociedade. Ser mulher é um papel social. E, dessa forma, ser homem também. A pedagogia homossexual presente em diversas culturas, como na Grécia clássica, e o estudo de tribos da África Oriental e Nova Guiné (BADINTER, 1993) nos demonstram bem isso. Para que o indivíduo se torne "homem", é preciso "tirar" a mulher de dentro dele, num claro exercício de expurgo de toda uma relação de identidade e afetividade que este possa ter construído com a mãe. Pela lógica proposta - que é uma ideologia - o homem deve nascer de outro homem, ou de um grupo de homens; do menino irá nascer o homem a partir de um ritual social. Essa forma de pensar, apesar de nos parecer estranha, continua viva em grupos sociais, associações desportivas, agremiações recreativas e em ritos adaptados a contemporaneidade. Tal ideologia está enraizada em nosso cotidiano, em nossos desejos mais simples, e acaba por se materializar em nossas ações corriqueiras.

Carlota consegue fazer com que o pai e o noivo - O Conceição - a levem ao teatro.

3 Ideologia é tomada aqui no sentido mesmo que Gramsci lhe deu, como um discurso produzido por uma classe dominante, em uma sociedade histórica, para a construção de um imaginário comum com o intuito de dissimulação do real. 
Lembremos que, na prática do século XIX, a passividade da mulher derivava também de sua estrita dependência financeira. No terceiro ato, o Conceição a questiona sobre a curiosidade primeira. Se conseguira, por fim, entender o que viria a ser o casamento. Carlota não lhe dá muita atenção e se mantém atenta ao palco; vigilante e esperançosa. Ela fala francês, como todas as moças educadas na corte carioca, toca bem o piano, consegue bons resultados tanto no bordado como nas conversas com famílias amigas, em sua casa; é casta, pura. Seria fiel ao marido assim como o fora à família antes do casamento. Tinha - afora a curiosidade todos os impulsos sob estrito controle. Assim fora ensinada. O que mais seria preciso?

Sabemos que os padrões de comportamento da sociedade acompanham as mudanças no cenário político que vem a acontecer no Brasil desde o início do século XIX, isso foi sentido também no modelo da família. Com o fortalecimento econômico do Rio de Janeiro capital do reino - a riqueza passa a fazer parte da cidade e o comércio se desenvolve grandemente. Com o fim da escravidão e a chegada contínua de imigrantes (e migrantes), o desenvolvimento de uma indústria incipiente, o modelo tido como "ideal" de família também lentamente se transforma. A chamada "família conjugal", restrita basicamente ao marido, a mulher e poucos filhos - excluindo o conjunto de parentes sanguíneos ou não que caracterizava a família patriarcal - e onde a escolha do companheiro não obedece a questões de interesse financeiro ou a preservação de oligarquias da terra se torna predominante.

Com isso, as relações entre os gêneros tendem a ser mais igualitárias, mesmo considerando que a dominação da mulher pelo homem não tenha terminado. Algumas tolerâncias, como o adultério masculino e a permissividade para com a prostituição como uma espécie de pedagogia sexual para os jovens rapazes tendem a permanecer, ao mesmo tempo em que a total intolerância com a infidelidade feminina, vista, no caso das relações entre os gêneros, como a mulher sendo ainda uma propriedade do homem (CÂNDIDO, 2011). A mulher, apesar disso, começa a ter um espaço fora do ambiente doméstico, com a possibilidade de instrução escolar nos primeiros grupos formados para tal fim e a ocupar também um espaço no mercado de trabalho, seja no caso das famílias mais pobres em que a mulher e filhos devem trabalhar para auxiliar o sustento da família, seja em grupos mais abastados, por uma escolha pessoal da mulher.

A família conjugal passa, ao menos no espaço urbano, a ser o modelo predominante. $\mathrm{O}$ casamento é uma forma de libertação para a mulher do domínio do pai; com o marido, a "luta" acaba tendo um grau de desigualdade menor. É nessa categoria que encontramos a maior parte da população, de trabalhadores e trabalhadoras que sobrevivem dentro de um país que se esforça por implementar suas primeiras indústrias, atentando para a mão de obra barata que possa conseguir. O que não quer dizer que as modificações na visão sobre o trabalho feminino, as conquistas de espaço no meio social, o início de uma estabilidade financeira - pela incapacidade de, na maioria dessas famílias, haja visto a impossibilidade (e mesmo a incapacidade) do homem cumprir sozinho o papel que lhe é (ainda é) atribuído de provedor familiar - não consegue apagar a existência do modelo anterior de família patriarcal que continua em algumas localidades, não como um fantasma a assombrar os cantos da casa, mas aceitando modificações e adaptações.

Apesar de que, observa-se, que algumas mulheres operárias não se opunham ao modelo tradicional de família em que o homem, conseguindo, se tornasse o provedor financeiro enquanto a esposa cuidava da conjunto da economia doméstica e dos filhos, o que existiu foi uma pressão econômica que, enquanto empurrava a mulher para fora de casa, não percebia que ao mesmo tempo minava as bases da dominação masculina (NADER, 2002, p. 473). Aqui podemos entender que as relações de família, casamento, homem e mulher modificam-se e adaptam-se as transformações históricas e sociais, o que vem redefinir continuamente as relações de poder entre os gêneros.

A mulher consegue, e isso se deve em muito, também, ás lutas encampadas pelos diversos movimentos feministas em fins do século XIX e início do século XX, conquistar espaços antes só destinados ao homem. Mesmo que tenha sido explorada - como muitas vezes ainda o é - reverte tal fatalidade em experiência e galga espaços importantes que não lhe seriam mais "retomados" nem no mercado de trabalho nem no ensino regular e superior; não apenas 
como alguém com experiência para melhor poder educar os filhos, mas como uma conquista que vem provar a igual capacidade entre os gêneros.. Nessa hora, Carlota estica o braço e espera por seu noivo na frente do camarote que, sem muito se preocupar com a questão e o desenrolar do espetáculo, se distrai conversando com outros homens. A solução para o enigma não pareceu agradá-la, visto deixar sobressair uma expressão de tédio e leve sonolência. $\mathrm{O}$ Conceição se coloca a seu lado, na porta do teatro, com um olhar sério e confiante a espera do Tílburi, como quem já tem garantido a posse de seus domínios. Carlota, por sua vez, recosta a cabeça e tenta dormir. Não mais falaria de suas agruras ao pai ou ao noivo, talvez nem mesmo à mãe. Era preciso, talvez soubesse, pensar nas instituições a partir do novo século e trabalhar para uma consolidação cada vez maior do papel social da mulher na relação entre os gêneros dentro da família e do casamento. Quem sabe poderia pensar - para entender melhor tudo isso, seria preciso esperar outro livro do Alencar?

\section{Referências}

1. ABRAMO, Cláudio Weber. Contos completos de Machado de Assis. Sítio eletrônico que abriga a antologia de contos de Machado de Assis. Disponível em $<$ www2.uol.com.br/machadodeassis $>$. Acesso em 03 de agosto de 2011.

2. BADINTER, Elisabeth. É o homem que engendra o homem. In . XY: Sobre a identidade masculina. 2ed. Rio de Janeiro; Nova Fronteira, 1993.

3. BEAUVOIR, Simone de. O segundo sexo. Difusão europeia do livro. São Paulo, 1970.

4. BRASIL. Constituição (1988). Constituição da República Federativa do Brasil: promulgada em 05 de outubro de 1988. Organização do texto: Juarez de Oliveira. 4a. Ed. São Paulo. Saraiva 1990.

5. CÂNDIDO, Antônio de Mello e Souza. The brazilian family. Versão eletrônica disponível em $<\underline{\text { http://www.bernardojablonski.com/ }}$ pdfs/pos/brazilian family.pdf $>$. Acesso em 05 de agosto de 2011.
6. CORREA, Mariza. Repensando a família patriarcal brasileira. (notas para o estudo das formas de organização familiar no Brasil) in ARANTES, Antônio Augusto (org.), Colcha de retalhos. Estudos sobre a família no Brasil, Campinas. Unicamp, 1993.

7. CHAUI, Marilena. Cultura e democracia. O discurso competente e outras falas. 7a. Ed. São Paulo: Cortez, 1997.

8. GRAMSCI, Antônio. Os intelectuais e a organização da cultura. Rio de Janeiro. Civilização Brasileira, 1982.

9. MatTos, Cristiane Araújo de. Dependência econômica e inadimplência: alternativas femininas para a sobrevivência após o divórcio. Dissertação de mestrado para o curso de História Social das Relações Políticas, da Universidade Federal do Espírito Santo. Vitória, 2008.

10. NADER, Maria Beatriz. A condição masculina na sociedade. In Dimensões. Revista de História da UFES. Vitória. Ed. da Universidade Federal do Espírito Santo, n. 14, 2002.

11. SAFFIOTI, Heleieth I.B. Rearticulando gênero e classe social. In COSTA, Albertina de Oliveira \& BRUSCHIN, Cristina (orgs.) Uma questão de gênero. Rio de Janeiro: Rosa dos tempos; São Paulo. Fundação Carlos Chagas. 1992. (pg. 183-215)

12. SCOTT, Joan Wallach. Gênero: uma categoria útil de análise histórica. In Educação e realidade. Porto Alegre,V.20, n2. 1995, pp. 71-99.

Endereço para Correspondência:

Rogério N. Afonso

atelierdissidencia@hotmail.com

Avenida Saturnino Rangel Mauro, 498 - Apt. 204

Jardim da Penha - Vitória - ES

CEP: 29060-770 